Artikel Penelitian

\title{
Median Ekskresi Yodium Urin pada Anak Usia 6-12 Tahun di SD Negeri 27 Olo Ladang Kecamatan Padang Barat Kota Padang
}

\author{
Mia Puspita ${ }^{1}$, Fadil Oenzil ${ }^{2}$ Erlina Rustam ${ }^{3}$
}

\begin{abstract}
Abstrak
Seseorang bisa mengalami Gangguan Akibat Kekurangan Yodium (GAKY) apabila asupan yodium tidak mencukupi. GAKY biasanya ditemukan di daerah pegunungan, namun sekarang GAKY juga ditemukan di dataran rendah bahkan di daerah pantai, seperti yang terjadi di gugus pulau Halmahera Utara-Barat. Tujuan penelitian ini adalah untuk melihat gambaran ekskresi yodium urin pada siswa usia 6-12 tahun di SD Negeri 27 Olo Ladang. Sekolah ini merupakan salah satu sekolah yang berada di sekitar pantai di kota Padang. Penelitian ini adalah studi deskriptif dengan desain cross sectional yang dilaksanakan dari November 2012 sampai Juli 2013 di SD Negeri 27 Olo Ladang Padang. Subjek penelitian adalah 62 siswa sekolah dasar yang telah memenuhi kriteria inklusi, kemudian diambil urinnya untuk dilakukan pemeriksaan kadar yodium. Hasil analisis univariat menunjukkan bahwa dari 62 subjek penelitian, $22(35,5 \%)$ diantaranya memiliki nilai ekskresi yodium urin tidak mencukupi, 38 (61,3\%) memiliki ekskresi yodium urin cukup, $1(1,6 \%)$ memiliki ekskresi yodium urin lebih dari cukup, dan $1(1,6 \%)$ memiliki ekskresi yodium urin berlebihan. Hasil yodium tersebut, nilai median dari ekskresi yodium urin para responden adalah 118,5 $\mathrm{gg} / \mathrm{L}$. Hal ini berarti bahwa intake yodium para siswa di SD Negeri 27 Olo Ladang telah mencukupi kebutuhan.

Kata kunci: ekskresi yodium urin, GAKY, anak
\end{abstract}

\begin{abstract}
One can experience lodine Deficiency Disorders (IDD) if insufficient iodine takes place. IDD is usually found in mountainous areas, but now the IDD is also found in the lowlands, even the coastal areas, as it happened in the group of islands on the North-West Halmahera. The objective of this study was to see the description of the urinary iodine excretion in the 6 - 12 years old students in The State Elementary School Number 27 Olo Ladang, which is located around the coastal area of Padang. This study was a descriptive research with the cross sectional design that conducted in November 2012 to July 2013 in The State Elementary School Number 27 Olo Ladang, Padang. The subjects were 62 elementary school students who have met the inclusion criteria. Their urine were taken for examination of the urine iodine levels. Results of univariate studyshow thatfrom 62 subjects of the study, $22(35,5 \%)$ of them had insufficient urinary iodine excretion, $38(61,3 \%)$ of them had sufficient urinary iodine excretion, $1(1,6 \%)$ of them had more than sufficient urinary iodine excretion, and $1(1,6 \%)$ of themhad excessive urinary iodine excretion. Median value of the urinary iodine excretion respondents is $118,5 \mu \mathrm{g} / \mathrm{L}$, indicate adequate iodine intake and optimal iodine nutrition.
\end{abstract}

Keywords: urine lodine excretion, IDD, child

Affiliasi penulis: 1. Prodi Profesi Dokter FK Unand (Fakultas Kedokteran Universitas Andalas Padang), 2. Bagian Biokimia FK Unand. 3. Bagian Farmakologi dan Terapeutik FK.Unand.

Korespondensi: Mia Puspita, email: miadori19@gmail.com, Telp: 085278099928

\author{
PENDAHULUAN \\ Yodium merupakan "trace elements" yang \\ dibutuhkan tubuh sebagai bahan dasar dalam \\ pembentukan hormon tiroid. Apabila tubuh manusia
}


kekurangan yodium, maka pembentukan hormon tiroid akan berkurang, sehingga terjadi peningkatan pembentukan TSH oleh hipofisis dan merangsang peningkatan aktifitas tiroid yang berujung pada pembesaran kelenjar. ${ }^{1}$ Bahan makanan yang banyak mengandung yodium adalah "seafood", selain itu juga terdapat dalam buah-buahan dan sayuran seperti stroberi, apel. dan jeruk, tergantung pada kandungan yodium dalam tanah dan air tempat tumbuhan tersebut ditanam ${ }^{2}$

\section{Gangguan Akibat Kekurangan Yodium (GAKY)} sering ditemukan pada daerah terpencil dan terisolasi yang mengonsumsi makanan hanya dari produk yang mereka tanam sendiri. ${ }^{3}$ Selain di pegunungan, penyakit gondok juga ditemukan di dataran rendah seperti Finlandia, Belanda, dan bahkan di daerah pantai, seperti di Yunani, Jepang, Pantai Kebumen di Jawa Tengah dan Kepulauan Maluku. ${ }^{2}$

Banyak masyarakat yang kurang memahami manfaat yodium. Pada tahun 1990, lebih dari 1,57 miliar penduduk di bumi ini menderita defisiensi yodium. ${ }^{4}$ Sekitar 50 juta anak mengalami gangguan akibat kekurangan yodium dalam berbagai derajad, dan setiap tahunnya didapati 100 ribu kasus kretin baru. ${ }^{5}$

Asia tenggara merupakan penyumbang paling besar kasus GAKY di dunia, yaitu sekitar 486 juta penduduk nya didapati mengalami kekurangan yodium, terutama di negara Indonesia, Myanmar, dan Thailand. ${ }^{5}$ Jumlah penderita GAKY di Indonesia mencakup lebih dari 14 juta penduduk, 750 ribu orang menderita kretin, 10 juta orang menderita gondok, dan 3,5 juta orang menderita gangguan lain. ${ }^{6}$

Tahun 1980, di Asia Tenggara dan India terjadi perubahan epidemiologi kejadian penyakit gondok. Penyakit gondok tidak hanya ditemukan di daerah pegunungan sebagai akibat pengikisan yodium oleh air hujan, tapi juga ditemukan di daerah dataran rendah, di sepanjang aliran sungai, dan bahkan disekitar pantai. ${ }^{7}$

Berdasarkan hasil Survey Nasioal Gondok tahun 1980/1982 dan hasil survey tahun 1995/1996, gugus pulau Halmahera Utara-Barat memiliki TGR $54,7 \%$, ini berarti wilayah ini termasuk endemik berat, padahal di wilayah Kabupaten Halmahera Utara merupakan kawasan pesisir, dimana memiliki sumber daya alam yang mengandung cukup yodium, seperti ikan dan rumput laut. ${ }^{8}$ Hasil pemetaan GAKY nasional tahun 1996/1998, didapati juga bahwa daerah pantai di Maluku termasuk daerah gondok endemik. ${ }^{9}$ Kejadian gondok yang meningkat di dataran rendah dan daerah sekitar pantai menunjukkan telah terjadi transisi epidemiologi.

Indikator yang dapat dipakai dalam menilai gangguan akibat kurang yodium dalam suatu populasi adalah mengukur kadar yodium yang di ekskresikan dalam urin.Kadar yodium dalam urin dapat menggambarkan intake yodium seseorang. Penelitian yang dilakukan oleh Rasmussen et al menemukan bahwa pada daerah dengan defisiensi yodium ringan, intake yodium (mean $89 \pm 6,5 \mu \mathrm{g} / \mathrm{hari}$ ) memiliki korelasi dengan ekskresi yodium urin ( mean UI $95 \pm$ $5,3 \mu \mathrm{g} /$ hari). ${ }^{10}$

Penelitian ini dilakukan dengan tujuan untuk mengetahui angka kejadian gangguan akibat kekurangan yodium pada anak usia 6-12 tahun di daerah sekitar pantai di kota Padang dengan mengukur kadar yodium urin pada siswa yang bersangkutan.

\section{METODE}

Jenis penelitian adalah studi deskriptif. Populasi penelitian adalah siswa sekolah dasar yang berusia 6-12 tahun di SD Negeri No. 27 Olo Ladang Kecamatan Padang Barat Kota Padang.Sampel berjumlah 62 orang yang diambil berdasarkan metode simple random sampling. Kriteria inklusi sampel adalah murid SD Negeri 27 Olo Ladang kelas satu sampai lima, berusia 6-12 tahun, bersedia ikut dalam penelitian, memperoleh izin dari orang tua, bermukim di sekitar pantai Padang. Kriteria eksklusi antara lain tidak berada di tempat sewaktu melakukan penelitian, tidak bersedia diambil urinnya untuk pemeriksaan kadar yodium urin, sudah menarche/ mimpi basah, memakan makanan tinggi yodium sesaat sebelum pengambilan urin. Penelitian dilakukan dari November 2012 sampai Juli 2013.

Ekskresi yodium urin adalah indikator yang dipakai untuk menilai jumlah asupan yodium yang masuk bersama makanan. Status intake yodium 
seseorang pada dasarnya lebih akurat dinilai melalui pemeriksaan yodium urin yang dikumpulkan selama 24 jam. Namun metode ini sulit dikerjakan karena pengumpulan urin 24 jam kurang praktis, selain itu hasil pemeriksaannya kurang dapat dipercaya karena besarnya kemungkinan terjadinya pengumpulan urin yang tidak benar dan tidak komplit. ${ }^{11}$ Oleh karena itu penelitian ini menggunakan urin sewaktu untuk melakukan pemeriksaan kadar yodium.

Kadar yodium dalam urin akan diperiksa dengan metoda APDM (Ammonium Persulfate Digestion Methode).Hasil ukurnya yaitu (1) Tak

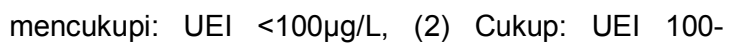

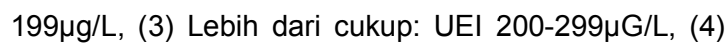

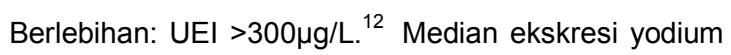
urin: merupakan nilai tengah untuk hasil pemeriksaan yodium urin pada semua responden. Pertama; hasil yodium diurutkan dari yang paling rendah sampai yang paling tinggi. Kedua; diambil nilai tengahnya. Suatu populasi dianggap mendapat asupan yodium yang cukup apabila median yodium dalam urin bernilai $100-$ $199 \mu \mathrm{g} / \mathrm{L}$ dan tidak lebih dari $20 \%$ sampel dengan kadar yodium urin dibawah $50 \mu \mathrm{g} / \mathrm{l}^{13}$

Pengolahan data dilakukan secara manual. Analisis data merupakan analisis univariat.

HASIL

Tabel 1. Distribusi frekuensi responden berdasarkan masukan yodium

\begin{tabular}{lcc}
\hline Masukan yodium & Frekuensi & $\%$ \\
\hline Tidak mencukupi & 22 & 35,5 \\
Cukup & 38 & 61,3 \\
Lebih dari cukup & 1 & 1,6 \\
Berlebihan & 1 & 1,6 \\
Jumlah & 62 & 100 \\
\hline
\end{tabular}

Tabel 1 menunjukkan dari 62 responden, 22 $(35,5 \%)$ diantaranya memiliki asupan yodium tidak mencukupi, 38 (61,3\%) memiliki asupan yodium cukup, $1(1,6 \%)$ memiliki asupan yodium lebih dari cukup, dan $1(1,6 \%)$ memiliki asupan yodium berlebihan.

Tabel 2 menunjukkan bahwa dari 62 responden, yang memiliki kadar yodium dalam urin $<50 \mu \mathrm{g} / \mathrm{L}$ adalah 4 orang $(6,5 \%)$. Ini berarti bahwa tidak lebih dari $20 \%$ dari total responden yang memiliki yodium $<50 \mu \mathrm{g} / \mathrm{L}$.
Tabel 2. Distribusi frekuensi responden berdasarkan kadar yodium dalam urin

\begin{tabular}{lcc}
\hline UEI $\boldsymbol{\mu g} / \mathbf{L}$ & Frekuensi & $\%$ \\
\hline$<20$ & - & - \\
$20-49$ & 4 & 6,5 \\
$50-99$ & 18 & 29,0 \\
$100-199$ & 38 & 61,3 \\
$200-299$ & 1 & 1,6 \\
$>300$ & 1 & 1,6 \\
Total & 62 & 100 \\
\hline
\end{tabular}

Pada Gambar 1 menunjukkan bahwa dari 22 responden yang memiliki yodium urin tidak mencukupi jika dilihat dari jenis kelamin, tidak menunjukkan perbedaan jumlah yang terlalu jauh, dimana 12 responden $(54,5 \%)$ berjenis kelamin perempuan, dan sisanya 10 responden $(45,5 \%)$ berjenis kelamin lakilaki.

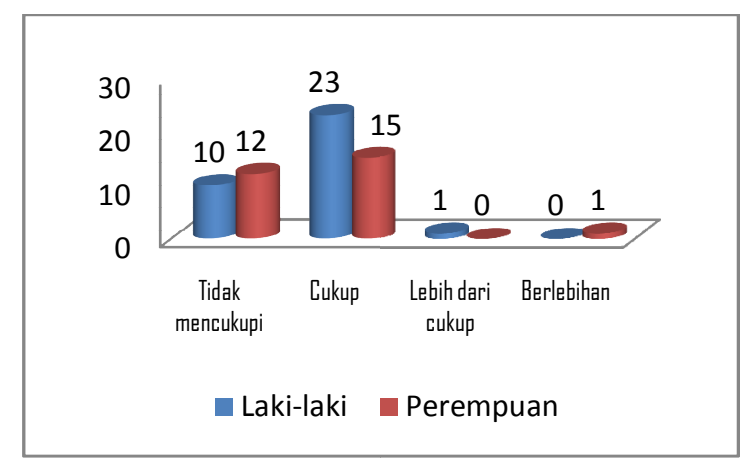

Gambar 1. Hasil pemeriksaan yodium urin berdasarkan jenis kelamin

Berdasarkan hasil pemeriksaan pada 62 responden, dapat ditarik kesimpulan bahwa nilai median yodium urin yaitu $118,5 \mu \mathrm{g} / \mathrm{L}$. Nilai median didapat dengan cara mengambil nilai tengah dari hasil pemeriksaan yodium urin yang telah diurutkan dari nilai paling rendah ke nilai paling tinggi. Ini berarti bahwa nilai median yodium urin masih berada pada batas cukup.

\section{PEMBAHASAN}

Penelitian ini dilakukan pada tahun 2013 terhadap siswa-siswi SD Negeri 27 Olo Ladang, sebagai salah satu sekolah yang berada disekitar pantai di Kota Padang. Hasil penelitian menunjukkan bahwa sebagian responden memiliki nilai eksresi 
yodium urin tidak mencukupi $(<100 \mu \mathrm{g} / \mathrm{L})$, yaitu mencakup $35,5 \%$ dari total responden (62 siswa). Sedangkan siswa yang memiliki nilai yodium cukup (100-199 $\mu \mathrm{g} / \mathrm{L})$ yaitu $61,3 \%$, yodium lebih dari cukup (200-299 $\mu \mathrm{G} / \mathrm{L})$ yaitu $1,6 \%$ dan yodium berlebihan (>300 $\mu \mathrm{G} / \mathrm{L}$ ) yaitu $1,6 \%$. Responden yang memiliki nilai yodium urin tidak mencukupi jika ditinjau dari jenis kelamin tidak didapati perbedaan yang terlalu jauh antara laki-laki dan perempuan, dimana 12 responden $(54,5 \%)$ berjenis kelamin perempuan, dan sisanya 10 responden $(45,5 \%)$ berjenis kelamin lakilaki.

Hasil pemeriksaan yodium pada kesemua responden tersebut didapati nilai median dari ekskresi yodium urin para responden adalah $118,5 \mu \mathrm{g} / \mathrm{L}$. Sedangkan responden yang memiliki nilai yodium urin $<50 \mu \mathrm{g} / \mathrm{L}$ adalah 4 orang, yaitu $6,5 \%$ dari total responden. Nilai median yodium urin nya cukup dan responden dengan yodium urin $<50 \mu \mathrm{g} / \mathrm{L}$ kurang dari $20 \%$, ini mengindikasikan bahwa intake yodium pada populasi di SD Negeri 27 Olo Ladang telah mencukupi.

Nilai median yodium urin dapat digunakan untuk mewakili status yodium pada suatu populasi, namun nilai median tidak dapat digunakan untuk membandingkan intake yodium perorangan. Median yodium urin biasanya dipakai apabila penelitian dilakukan pada responden yang jumlahnya sangat besar dan mencakup wilayah yang luas, sehingga nilai median dapat digunakan untuk membandingkan intake yodium populasi dari satu daerah dengan daerah lain. ${ }^{14}$ Penelitian ini menggunakan nilai median yodium urin karena urin yang diambil untuk pemeriksaan adalah urin sewaktu.

Hasil penelitian ini berbeda dengan hasil Survey Nasioal Gondok tahun 1980/1982 dan hasil survey tahun 1995/1996, dimana gugus pulau Halmahera Utara-Barat memiliki TGR $54,7 \%$, ini berarti wilayah ini termasuk endemik berat, karena memiliki TGR $>30 \%$. Jika dilihat dari nilai median yodium urin, suatu daerah dikatakan endemik berat apabila memiliki nilai median yodium urin $<20 \mu \mathrm{g} / \mathrm{L}$. Padahal wilayah Kabupaten Halmahera Utara merupakan kawasan pesisir, dimana memiliki sumber daya alam yang mengandung cukup yodium, seperti ikan dan rumput laut. ${ }^{8}$
Penelitian ini juga berbeda dengan hasil yang didapatkan oleh Li Mu et al pada tahun 2008 di Pulau Tanna, Republik Vanuatu. Didapati bahwa 153 siswa di 14 sekolah di sana memiliki median yodium urin 49 $\mu \mathrm{g} / \mathrm{L}$, dimana $51 \%$ nya memiliki yodium urin $<50 \mu \mathrm{g} / \mathrm{L}$. Ini berarti bahwa Pulau Tanna merupakan daerah endemik sedang. Padahal jika dilihat dari wilayahnya, Pulau Tanna merupakan daerah sekitar pantai. ${ }^{15}$

Studi ini hanya dilakukan pada satu sekolah dasar, sehingga belum bisa mewakili daerah pantai secara keseluruhan. Perlu penelitian lebih lanjut dengan melakukan pemeriksaan di SD lainnya di sekitar pantai padang untuk memastikan telah terjadinya transisi epidemiologi kasus GAKY dari daerah pegunungan ke daerah pantai, khususnya di Kota Padang.

Dalam melaksanakan penelitian ini terdapat beberapa keterbatasan, diantaranya yaitu responden adalah siswa sekolah dasar yang masih tergolong anak-anak, sehingga peneliti menemui sedikit kesulitan dalam menjelaskan tujuan penelitian kepada siswa. Sebagian besar responden juga lupa mengembalikan informed consent yang telah dibagikan, walau peneliti sudah mengingatkan responden 3 hari berturut-turut. Akibatnya peneliti hanya meminta tanda tangan responden tanpa adanya tanda tangan dari orang tua. Hampir sebagian besar siswa menolak untuk ditemani saat pengambilan urin. Walau sebelumnya peneliti mengingatkan agar yang ditampung hanyalah urin, tetapi peneliti tetap tak bisa memastikan apakah urin tercampur dengan air.

\section{SIMPULAN}

Nilai median yodium urin dari seluruh responden yang diperiksa yaitu $118,5 \mu \mathrm{g} / \mathrm{L}$, yang berarti intake yodium masih mencukupi.Siswa SD N 27 Olo Ladang yang memiliki nilai eksresi yodium urin dibawah normal $(<100 \mu \mathrm{g} / \mathrm{dl})$, yaitu $35,5 \%$. Siswa yang memiliki nilai yodium urin $<50 \mu \mathrm{g} / \mathrm{L}$ adalah $6,5 \%$, (masih berada di bawah 20\%).

\section{DAFTAR PUSTAKA}

1. Gibney, Michael J, Barrie M, Margetts, John M, Kearney. Gizi Kesehatan Masyarakat (terjemahan). Jakarta: EGC; 2009. 
2. Sudoyo AW. Dalam: Sudoyo AW, Setiyohadi B, Alwi I, Simadibrata M, Setiati S, editor (penyunting). Buku ajar ilmu penyakit dalam. Jakarta: Pusat Penerbitan Departemen IImu Penyakit Dalam FKUI; 2009.

3. Geissler, Catherine, Powers H. Human nutrition. Edisi ke-7. London: Elsevier Churchill Livingstone; 2005.

4. Delange F, Bruno Db, Hans B, \& ICCIDD Working Group. Determining median urinary iodine concentration that indicates adequate iodine intake at population level. Bulletin of the World Health Organization. 2002;80: 633-6.

5. Quazi, Salamatullah, Mohiduzzaman M, Moududur RK, BNahar, M Mostafizur, Rahman, et al. Urinary iodine levels in three ecological zones of Bangladesh. Indian Journal of Clinical Biochemistry. 1997;12(2):128-33.

6. Arisman. Gizi dalam daur kehidupan. Jakarta: EGC; 2004.

7. Guyton A, Hall JE. Buku ajar fisiologi kedokteran (terjemahan). Jakarta:EGC; 2008.

8. Bitjoli, Catrintje D, Haluan J, Simbolon D. Identifikasi kondisi dan status gizi masyarakat pesisir Kabupaten Halmahera Utara. In Press; 2009.

9. Departemen Kesehatan RI. Survei nasional pemetaan gangguan akibat kekurangan yodium
(GAKY). Kerjasama Pusat Penelitian Gizi dan Makanan dengan Direktorat Gizi. Laporan Akhir. 1998.

10. Rasmussen LB, Ovesen L, Christiansen E. Day-today, and within-day variation in urinary iodine excretion. Eur J Clin Nutr. 1999;53(5):401-7.

11. World Health Organization Nutrition Unit. Indicators for assessing iodine deficiency disorders (IDD), and their control through salt iodization. Geneva: WHO; 1994.hlm.36.

12. WHO, UNICEF, ICCIDD. Progress towards the elimination of iodine deficiency disorders (IDD). Geneva: WHO;1999 Document WHO/NHD/99.4.

13. WHO, UNICEF, ICCIDD. Assessment of the iodine deficiency disorders and monitoring their elimination. Geneva:WHO; 2001 Document WHO/ $\mathrm{NHD} / 01.1$.

14. Nystrom HF, M Andersson, G Berg, R Eggertsen, E Gramatkowski, M Hansson, et al. Thyroid volume in Swedish school children: a national, stratified, population-based survey. European Journal of Clinical Nutrition. 2010; 64:1289-95.

15. Li Mu, McKelleher N, Moses T, Mark J, Byth K, Gary Ma, Creswell JE. Iodine nutritional status of children on the island of Tanna, Republic of Vanuatu. Public Health Nutrition. 2008;12(9): 1512-8. 